\title{
Application and Development Trend of Integrated Supply Chain in China
}

\author{
HUANBIAO CHEN \\ COSFIM OY, FINLAND
}

\section{Zusammenfassung}

Die eingeführte integrierte Beschaffungskette verändert die chinesische Logistik, d.h: von normaler Fracht bis zu der Herstellung der Produkte, Warenumlauf und Ausschöpfung des Logistiksystems. Verschiedene Arten der integrierten Beschaffungskette werden in den unterschiedlichen Firmen angewendet, somit verfügt diese Beschaffungskette über noch mehr Leistung und Effizienz. Die Tendenz der integrierten Beschaffungskette in China fördert die Verbesserung des E-Commerce und des Kundenservices in der Zukunft. Das kombinierte chinesische Logistiksystem erweitert die chinesische Logistik. Sie wird noch internationaler und weltweiter sein.

\begin{abstract}
Importing integrated supply chains have changed Chinese logistic from simplex freight to the process of product of production, circulation and consumption of logistic system. Different modal of integrated supply chain apply in the different companies, bring activity and efficiency integrated supply chain in China. The trend of Chinese integrated supply chain in the future will stress on e-commerce and customer service, and combined Chinese own logistic system to enlarge Chinese logistic, which will more international and world wild.
\end{abstract}

\section{Introduction}

The concept formation and scientific management establishment of logistics have only several tens of years' history and it was officially introduced into China merely over ten years ago. The formation history of logistics was actually as early as when the commodity exchange appeared in the human society, due to the development of economy. Modern logistics has already become one of the most widespread industries.

From the Chinese traditional point of view, transportation is the foundation of national economy development. With rapid social, economical, and technical development, and with unceasing consumption of each kind of infrastructure, global economic integration tendency and highly fierce market competition, people have changed their viewpoints. For the past few years, logistics management and logistics technology have been obtained widespread acknowledgement, application and development in the industrial developed countries. People have already realized that, transportation, and logistics system formed in the product production, circulation and consumption processes, have become the important foundation of national economy at a high sustainable development point. In addition, with the modern science and technology, management and information technology widely used in logistics system, logistics has become one of basic industries that impel market economy.

In China, a new kind of thinking and idea is needed to form entire logistics system to regard sustainable development on social and economic activities such as Chinese production, circulation, consumption, and etc. In the past planned economy, production and circulation in the economic activities were treated as two isolated essential factors; even transportation was divided into a lot of non-relational processes. At present, with the gradual establishment of market economy, this kind of mode has changed - mutual boundary is gradually broken.

\section{Current economic environment of Chinese logistics}

After 20 years of Chinese reform and opening up, Chinese economy has obtained the unprecedented development in the switch process from the planned economy to the market economy. National economy is greatly enhanced; market economy is forming, and the once long-standing short condition in the national 
economy developing process has ended. Since the later 90's, Chinese economy faced complex phases and challenge, because of the influence of Asian financial crisis, and day by day exacerbated contradiction between insufficient domestic demand and market surplus. Presently, Chinese economy is in the period of an important structure transformation. The existing economic and industrial structure obviously drop the support ability to continuous and fast growth of national economy under the environment of steady buyer market and domestic and foreign market demand restraint. The main reason is that the production supplies structure cannot adapt consumption (productive consumption and lives expends) change. For many years, intersected investment system has impelled excessive redundant construction projects, resulting in unreasonable structure of organizations and productive forces and over- competitive. Moreover consumption mode promotion has undergone a lot of difficulties because present system and policy factor restrict it.

Under the major tendency of current global economic integration, China, the biggest developing country in the world, undergoes from a shortage economy in a lower overall economy development to a buyer market. It not only reflects the quantity increases in the social product supply ability, but also profoundly reflects qualitative change in the economical quality. Growth method of national economy becomes the principal contradiction in the current economy development. It symbolizes that the current Chinese economy development changes from the resources restraint to the demand restraint as main body. The main barrier in economical development does not merely exist in the realm of production, whereas it already starts to shift to the circulation and consumption domain. Since Chinese reform and opening up, the fast growth of China national economy has been impelled by the industrial capital expansion in realm of production and expediting of the industrialization advancement. However, circulation between the production and the consumption does not adequately adapt the industrialization level of development. A same badly-managed state-owned enterprise as host channels weakens and commercial credit decreases. The circulation mode that sole traders and private owners are the main part of trade market is becoming the main channel to supply daily consumable in towns. The high decentralized business management in circulation industry not only makes the cost of commodity circulation increase, but also it will become a barrier of production development and consumption enlargement.

\section{Chinese integrated logistics and supply chain management}

Integrated logistics is one of most influential logistics tendencies in the late $20^{\text {th }}$ century. Its basic content is to achieve desired impact such as enhancing the logistics efficiency, reducing the logistics cost through the cooperation of logistics systems, among different function departments or different corporations. Integrated logistics includes three forms vertical integrated logistics, horizontal integrated logistics, and logistics network. Among these, the vertical integrated logistics is has found the widest applications.

The vertical integrated logistics requests that enterprises should bring suppliers, which supply products or offer transport services, and users into their own management, and consider this part as a central content in the logistics management. The vertical integrated logistics also requests that enterprises should realize the logistics management in each process from the raw and processed materials to user. In addition, enterprises should use their own conditions to set up and develop the cooperation relationship with suppliers and customers in order to be competitive. The idea of the vertical integrated logistics is to offer a convenient way to solve complex logistics problems. Solid matter and technology base, advanced management methods, and communication technology make this idea come true and develop.

Intensive studies of vertical integrated logistics, have been conducted. Under the background of corporation collectivization and internationalization, American Michael Porter first proposes concept "value chain" and relative integrated supply chain theory based. Supply chain is an upstream and downstream industry integrated system composed of many corporations providing products or services to end customers in all sectors. Supply Chain Management (SCM) emphasizes the collaboration between core enterprises and correlated enterprises. Business management integration is realigned through information sharing, technology decentralization (communication and cooperation), optimized resource configuration and effective supply chain prompting mechanism and other methods. Actually, supply chain can be considered a kind of vertical integrated logistics, which satisfies customers' needs from the system's point of view by harmonizing material, capital and information flow in the whole process including production of raw material, semi-manufactured goods and finished product, supply, sale, to end consumption. Consequently, supply chain management is an integrated management, which cares about product flow instead of traditional function division or partial efficiency.

Supply chain enlarges original logistics system. Not only extends it the traditional vertical integrated logistics, but also exceeds logistics itself. It fully considers the entire logistics processes and each kind of environmental factor that affects these processes. Supply chain develops by terms of material flow, information flow, capital flow and other directions. As a result, it forms a relative independent and completed system. 
At present, most enterprises adopt group, "hypothesized enterprise” or through established supply chain strategy union and other forms, which mutually hold share to integrate enterprises into the whole supply chain as a part, provide the greatest valued services to customers based on their requirements and maximize whole benefit of supply chain. Obviously, enterprises involved in a supply chain are interdependent; but in reality, they do not cooperate often among, because it is not possible to simultaneously achieve the benefit maximization on each sector in the whole supply chain. It is very common that pursuing the whole benefit maximization will weaken one or some sector. Quite often, these weaken economic entities cannot obtain satisfied compensation, which overwhelm their enthusiasm for taking part in the supply chain. The solution to this problem is longitudinal integration, which generally means the longitudinal mergence of property rights between upstream suppliers and downstream customers. This was once believed as just one kind of ideal organization mode before, nowadays enterprises pay more attention to its core business at present, namely, choosing the obvious superior services that they are good at. And others belong to "resources outsourcing" i.e. purchasing outside enterprise. At this time, as the weakened sectors, the corresponding enterprises may obtain bigger living space because other similar business enterprises withdraw from this market, as well as solve the problem by using scale economy or other methods. One enterprise can simultaneously define itself in the different supply chains, thus this enterprise may get many partial benefits from different supply chains. In addition, the lateral functions of horizontal integrated logistics to protect the whole benefits of enterprises from weakening.

Horizontal integrated logistics obtains benefits of scale economy through cooperation of many enterprises in the same industry on logistics. For example, different enterprises may use the same shipping way to carry on common transportation for different types of products. When the logistics scope is similar and the logistics quantity is relatively small, it is obviously not economical, several enterprises separately carry on logistics operations simultaneously. When an enterprise is shipping his own products, he should also ship other enterprises' products. As a result the enterprise logistics cost can be reduced from the enterprise, economic efficiency point of view and redundant work in the social logistics process can be decreased from social efficiency viewpoint. Obviously, the logistics processes of different products are inconsistent in the space, but also different in the time. Solution of these contradictions and differences, depend on grasping massive logistics requirements and logistics information center that offer supply ability information. Moreover, another important condition to realize horizontal integrated logistics is a great number of enterprises involved and attend huge amount of existent products, thus cooperation among enterprises is able to improve logistic performance. Of course, integration and standardization of products dispatching etc. cannot be neglected.

The third form of logistics integration is logistics network, which are the syntheses of vertical integrated and horizontal integrated logistics. When each sector of one integrated logistics simultaneously becomes a part in another integrated logistics, the relationships among enterprises based on logistics relationship will form a network, i.e. logistics network. This is an open system, which enterprises may join or withdrawal freely, it is especially useful can be used during the busiest service season.

The condition for that logistics network to exert scale economic function is integration, standardization, and modularization. In order to realize logistics network, first of all, a batch of superior enterprise should unite with productive industries to share market as a federation, which develops the indirect shared benefit union into a superior confederation and shares market, thereby, shares bigger quotient benefits. And then, superior logistics enterprises must also form the market development federation with the middle and small sized logistics enterprises, and utilize the relative stable and integrated marketing system to help production enterprises to open up new market. Thus, competitors become allies, and the logistics network becomes a cooperated organism that a production enterprise and a logistics enterprise can cooperate by multi-positions, vertical and horizontal overlapping, and mutual infiltrate. Moreover, due to applications of advanced information technology, when joined enterprises increase, scale benefit of the logistics network will appear. This also improves the social labour deep division, causes development of "third party logistics" and the greatly reduces logistics cost in the entire society.

In China, there exist the complexity of sale links, the distempered credit system, and second level wholesalers in the whole supply chain. Because of the development of electronic commerce, those enterprises that are engaged in electronic business between companies and companies, and dotcoms that aim at customer sale should have their places in the supply chain. In addition, supply chain includes not only the material flow between the partners, but also information and capital flows. Under many circumstances, it also includes document flow. 


\section{Supply Chain Management in enterprise}

Supply Chain Management concept was proposed in the middle 1980's. It is bases on one kind of viewpoint that enterprise should care about the corporation management effect according to the total cost of unilateral pursuing which optimizes some functions such as purchase, production, and so on. The purpose of Supply Chain Management is to realize the best service achievements and improve the whole corporation business performance through harmonizing activities in each sector. High effective supply chain design, information sharing between supply chain members, stock visibility and good productive coordination can reduce stock level make effective transportation, and improve order realization ratio and other key service functions.

When each sector of supply chain cares only itself, and does not integrate its goals and activities with other departments, the entire supply chain will have unsatisfied performance. According to an American renowned management science professor says: supply chain management is "one kind of strategy based on the cooperation and it unites multi enterprises' service operation, in order to realize a common prospect of market opportunity". Obviously, each sector of supply chain has to carry on cooperation to optimization of supply chain. Why do more and more companies consider supply chain management as drive power of enhancing their competitive advantages and obtaining of profit ability? There may be five reasons as following:

\subsection{Increasing production ability}

Companies have recognized that the enhancement of internal production ability to improve investment income becomes more and more difficult. The cost of supply chain is huge, it is quite possible to increase production ability through improving supply chain management, and slight reduction of the cost of supply chain may exit obvious effect on the profit of the company to estimate the cost of supply chain in China. According to the current complex degree and status of infrastructure of supply chain in China, the reduction of cost could be between $30-50 \%$.

\subsection{Economic globalization}

In the worldwide scale, reduction of political bulwarks on international trade and investment and continuous decrease of international transport and communication cost make easier access to new market in the world. As for multinational corporations, effective international supply chain design and performance can possibly become the important discrimination factor and source of competitive power. Those multinational corporations that want to access to or have accessed to Chinese market, hardware and software of Chinese logistics services are unprecedented challenges. Meanwhile, this is a great opportunity for the Chinese logistics companies.

\subsection{Continuous change in service request}

Besides cost, time is also a competitive advantage. A sort of new competitive advantage emerges because of demand, i.e. providing maximum valuable services in the shortest time by the lowest cost. If products move slowly in supply chain, manufacturing companies that produce high technology products or other short lives circle products will suffer for ordinary wear and tear of products, i.e. heavy loss for obsolete products. In addition, some companies pay mare attention to launch new product to market and deliver them to consumers before developing new products by their competitors. These factors are impelling companies to adopt strategy of putting products into supply chain more quickly in order to obtain or maintain its competitive advantage.

\subsection{Enhancement of customer service level}

Under the conditions of the same product cost and quality, the companies that provide the best services for their customers will hold competitive advantage. Many customer service functions are correlative directly with supply chain. Delivering on time, reduction on order time, availability of products, making users understand order information in time and so on are correlative with the complex degree and implementation ability of supply chain. Continuous development on customer-oriented product also increases the supply chain complexity. Providing customer-oriented products and services for some special customer groups will lead to increase the types of products, outsourcing, and productive complexity and enhance the requirements for relative information volume and information flow. In China, the requirements of customer-oriented products stand out especially in high technology and electrical industries. Furthermore, in order to be closer to the customers' requirements, some Chinese leading enterprises, like KELON group a well-known group in electrical industry, and other enterprises, have already started an attempt to go towards this direction. 


\subsection{Anticipated high speed growth in electronic commerce}

Electronic commerce can largely affect supply chain and logistics operation of each company. Some leading Chinese electronic commerce companies have started to draw lessons from experience of overseas electronic commerce companies, they cooperate with professional logistics companies one by one, or unite strategy alliance, or hive off part of logistics operation to sub-contractors. Logistics companies also aim at this cosset of new economy - electronic commerce, and offer some special services in allusion to electronic commerce companies in succession.

\section{The development trend of the integrated supply chain in China}

Impelled by the economic globalization and the electronic commerce, the logistics which is transformed rapidly from the traditional logistics to the modern one, currently becomes the trend of the logistics development. Under the guidance of the systems engineering, taking the information technology as the core, strengthening resources conformity and optimizing the logistics of entire process are the most substantive characteristics of modern logistics. Internationally, the systematized integration application of two key technologies- the information technology and the standardization, revolutionarily affects the conformity and optimization of the logistics. Meanwhile, the application of key technologies such as network planning, the optimized theory and the method, automation, intelligence, as well as the application of new packing material and technology, give an impetus to the modern logistics obviously. Therefore, the logistics cost will be reduced greatly and the logistics will be innovated unceasingly with the support of new technical platform.

Nowadays, the large logistics service providers are devoting themselves to seeking the technical lead in the competition. The modern logistics technology development presents four main directions on the whole, namely, automation of logistics technical equipments, normalization of logistics operation management, intelligentization of logistics operation flows, and integration of many sorts of technologies and hardware / software platform. Comparatively, normalization, and integration of modern logistics develop rapidly, which is more popular in horizontal domain. In longitudinal domain, the development directions of logistic normalization are integration and intelligentization.

Because the logistics in China is not so advanced that the insufficient informatization degree has already become the most restrictive factor to the further development of logistics. At present, the industrial overall scale of logistics in China is still relatively small. According to an international research institute's estimate, the American third party logistics market scale equals approximately to $25 \%$ of the entire social logistics cost disbursement, and Europe is 30\%in Europe, aggregated level in Asia is lower than 5\%, while only about 2\% in China. Basically, primary part in the existing logistics service mode in China still is self-management, which lacks corresponding key technologies and information support. The proportion of third party logistics mode is small, and the level and the scale still cannot be satisfied, thus there are few enterprises that can provide, in the true sense, integrated modern logistics solutions. The fourth party logistics mode is still in the fundamental research and discussion stage. The results of an investigation to more than two hundreds logistics enterprises arranged by China Materials Storage \& Transportation Association (CMSTA) show, that the integrated logistics services in the whole processes provided by the third party logistics enterprises are less than $5 \%$ of the all requirements. This is an important factor to restrict logistics socialization service development in China.

Overall level of informatization in the Chinese logistics enterprise application of modern information technology and unbalanced development, in different regions of China cannot generally satisfy modern logistics requirements. The investigation on China logistics information system sponsored by China Storage Association (CSA) and published in 2003 until 2005 showed, in the 2003 there were about 59\% of Chinese logistics companies that had not information system support. And the rest, $41 \%$ did not have perfect information systems; in 2004 there are 77\% of logistics companies have information system support completely; 23\% did not; in 2005 there are $79 \%$ of logistics companies have information system support completely, $21 \%$ did not. Therefore the information system in the China are not used completely. Unadvanced modern logistics technology has become the urgent problem to be solved. See the figure 1: Chinese logistic information system. See figure: Chinese Logistic Information System. 


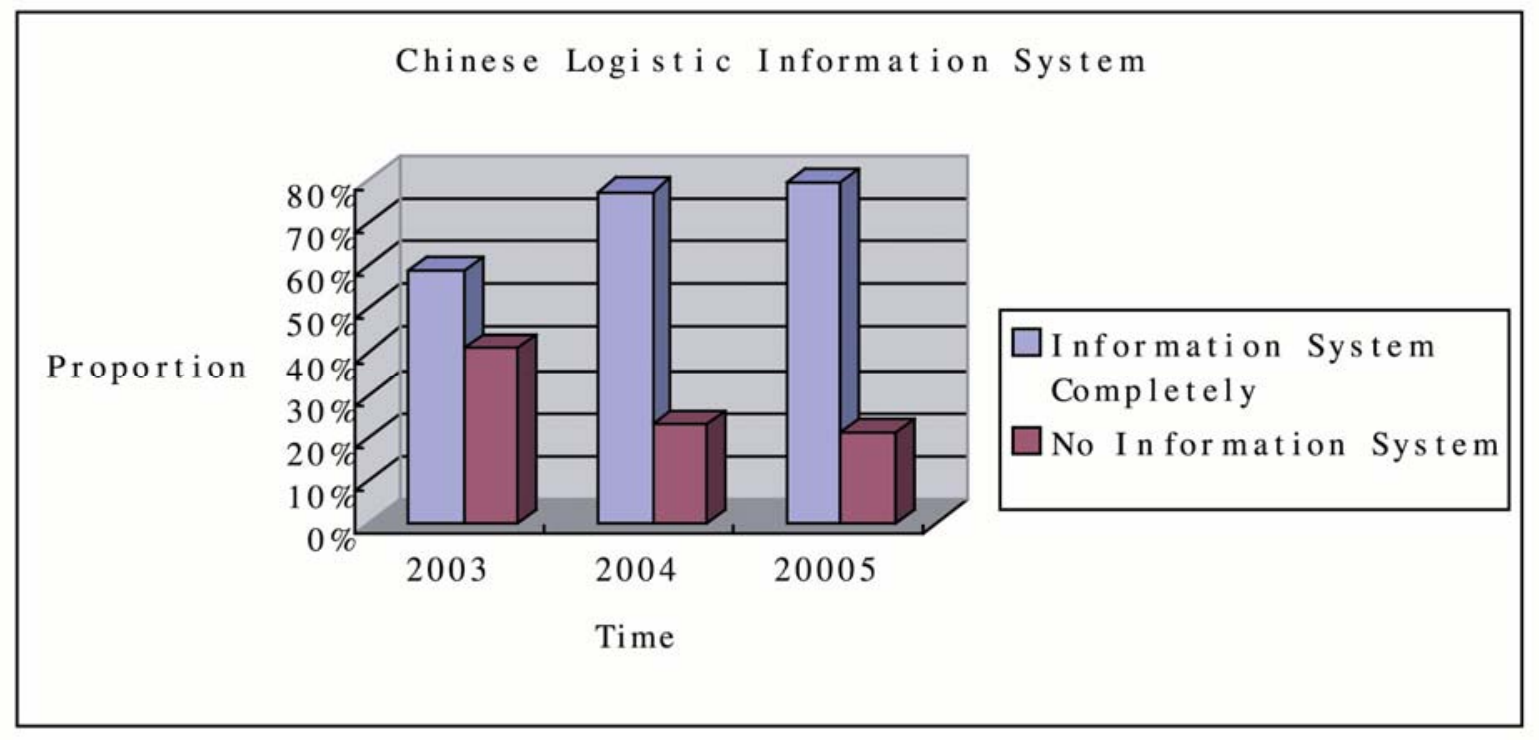

Figure 1: Chinese Logistic Information System

According investigate of analysis that in the logistic information function, the operation management and inquire function have occupy large proportion, it means in these companies management of position need to be rising, the core of logistic management are needed to be one step up.see figure 2. Chinese Information System Analysis.

\section{Proportion}

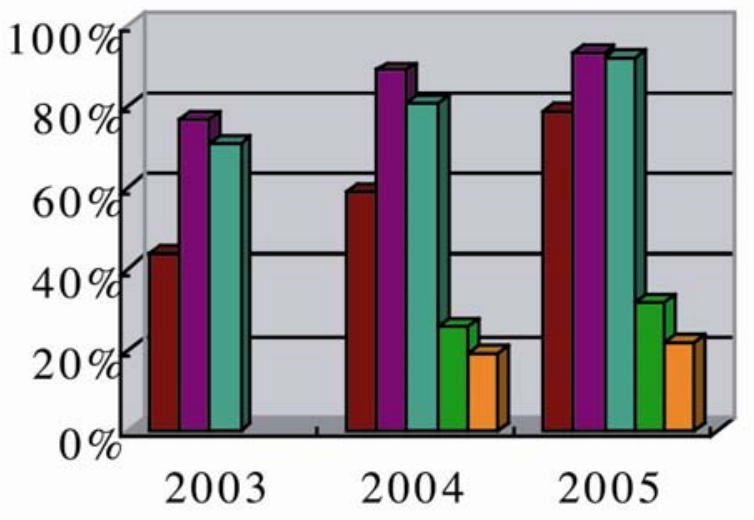

Informat i on

Operat i n

Mana ge ment

Demand Function

Optimize Analys is

Market Analysis

Time

Figure 2: Chinese Information Systems Analysis

Another important issue is that China logistics informatization should be supported urgently by corresponding environment. Because of the influence of logistics management system, there may be some problems in Chinese logistics such as conflicted standards, low degree standardization, limited applied scope for standardization, and insufficient implement force and so on. To some extent, the legislation power to logistics by government may be strengthen and suitable laws should be made and maneuverability of management rules and methods should be improved. Additionally, some authoritative organization may be set up to guide macroscopically and prompt technical communication in logistics technology area. In order to solve these problems, it is suggested that Chinese logistics should develop the following issues as key aspects: 


\subsection{Popularize Information technology}

The development of supply chain and logistics integration has under gone basic service execution, data collection / interior visualization, data connection, supply chain visualization and complex decision-making supply chain management stages. The higher complex degree the supply chain and logistics integration system has the greater benefits the enterprise may achieve. The current development on Chinese enterprise supply chain and logistics integration is between service execution and interior visualization, and efficiency of supply chain and logistics integration management should be enhanced. The development of Chinese modern logistics informatization should impel the integration of logistic horizontal and longitudinal activities, improve the industry-oriented and regional solutions, and realize the overall improvement in modern logistics operational quality.

\subsection{Speed up the standard system construction}

The logistics information system needs to unite each partner and each sector of the supply chain. Therefore, standardization should be made on the related code aspects such as coding, file format, data interface, EDI, GPS and so on. Meanwhile, the logistics software requires the industry standards from format and flow aspects in order to eliminate the information communication barrier between different enterprises and to create good environment for the construction of the enterprise logistics information system.

The horizontal integration of the logistics integration development is finally carried out on the platform of logistics public information. The collection of logistics information in each area provides the fundamental logistics information for the information systems such as the production, sale and logistics enterprises, satisfies the demands of logistics pubic information for the enterprise's information systems and supports to realize all kinds of functions of the systems. By sharing the logistics information, the industry management of the government departments and the cooperation mechanism in the aspect of the market standardization management may be established.

The most important functionality of the logistics public information platform is to integrate each kind of logistics information system's information resource in the region, to complete data exchange between various systems, to realize information sharing, to strengthen the cooperation between the logistics enterprises and the upstream/downstream enterprises, to form and optimize the supply chain is favorable to raise the utilization ratio of the social massive idle logistics resources. and it plays an important role in allocating the social logistics resources, optimizing society supply chain and straightening out economical chain. The logistics information platform construction is favourable to realize the joint with electronic commerce b2b (Business-to-Business) or b2c (Business-to-Consumer) system. Good logistics information platform should be a unified platform, which integrates highly with the electronic commerce system. It is a public service platform, which connects the government, industry and the enterprises. As an important part of modern service industry development in China, the logistics public information platform can enhance cooperation among the government, the profession and enterprise on a large scale, improve the enterprise's data connection and the supply chain visualization, reduce logistics society total cost generally, enhance the international competitive power of the state economy.

\subsection{Strengthen the construction of supply chain and logistics integration construction}

The longitudinal integration on logistics needs to strengthen the system construction of supply chain and logistics integration and emphasizes the system development on microscopic integration, self-integration and macroscopic integration. The core challenge is to develop advanced technologies. In recent years, governments, industries and enterprises have enlarged the investment on logistics information systems. However, as far as the overall implementation effect is concerned, there still is a universal existent problem, i.e. the total cost of logistics information system is high because of lacking available, advanced and economic basic key technologies. Therefore, emphasis should be put to carry on research and development on key and core technologies in modern logistics, reduce the overall cost be using advanced technologies, develop products that have Independent Intellectual Property Rights (IIPR), and strengthen the construction of information security and national security. The research and development on key technologies may include information collection, quick response, management control, bidirectional communications and other. 
In Chinese integration supply chain will keep to extend top of information technical, build a international standard logistic system and strengthen integration supply chain, it will getting mature day by day; therewith high speed improve for total level of Chinese logistic, a lower of information situation that Chinese will concentrate on the field of e-commerce.

\subsection{Conclusions}

Altogether, Chinese integrated supply chain is still kept toward to develop. Each aspect of economic activities, including production, consumption, as well as circulation that makes production and consumption link closely, is synthesized together by logistics, a burgeoning industry is formed, which considers market as its guidance, implements basic tenet to satisfy customer request, obtains optimized whole benefit, and adapts modern social economic development needs.

\section{References:}

http://www.sc.lead.cn

http://www.lunwenwang.com

http://www.caws.org.cn 